\title{
Accuracy of uniaxial accelerometer in chronic obstructive pulmonary disease
}

\author{
Marilyn L. Moy, MD, MSc; ${ }^{1-4 *}$ Eric Garshick, MD, MOH; ${ }^{2,4-5}$ Kirby R. Matthess, BS; $;^{2,4}$ Robert Lew, PhD; ${ }^{6}$ \\ John J. Reilly, MD $^{3-4}$ \\ ${ }^{1}$ Department of Veteran Affairs (VA), Veterans Health Administration, Rehabilitation Research and Development \\ Service, and ${ }^{2}$ Pulmonary and Critical Care Medicine Section, VA Boston Healthcare System, Boston, MA; ${ }^{3}$ Division of \\ Pulmonary and Critical Care Medicine, Department of Medicine, Brigham and Women's Hospital, Boston, MA; \\ ${ }^{4}$ Harvard Medical School, Boston, MA; ${ }^{5}$ Channing Laboratory, Department of Medicine, Brigham and Women's \\ Hospital, Boston, MA; ${ }^{6}$ Massachusetts Veterans Epidemiology Research and Information Center, VA Boston Health- \\ care System, Boston, MA
}

\begin{abstract}
Wearable sensors have been developed and used in nondisabled adults. Little is known about their accuracy in patients with chronic disease. We tested the ActiHealth accelerometer, which measures step counts, in subjects with chronic obstructive pulmonary disease (COPD). We determined the intra- and interdevice coefficients of variation (CVs). We assessed the accuracy of the device in 15 nondisabled males and 46 subjects with COPD. Accuracy was defined as percent step capture, (device step count divided by manual step count) times 100. Predictors of percent step capture were identified using linear regression methods. The accelerometer has an intradevice CV ranging from 0.008 to 0.025 and an interdevice CV of 0.64 . In nondisabled males, median percent step capture was $96 \%$ (interquartile range 81\%-98\%). In subjects with COPD, median percent step capture was $86 \%$ (interquartile range $72 \%-96 \%$ ). Usual walking speed was the most important predictor of percent step capture $(p=0.004)$. The ActiHealth accelerometer has acceptable intra- and interdevice CVs. It is highly accurate in nondisabled subjects. The accuracy declines in subjects with COPD based on walking speed. Prior to using the ActiHealth accelerometer, researchers and clinicians should assess walking speed and percent step capture in each subject.
\end{abstract}

Key words: accelerometer, ambulation, chronic obstructive pulmonary disease, COPD, pedometer, physical activity, rehabilitation, step count, walking speed, wearable sensor.

\section{INTRODUCTION}

Assessing ambulation and physical activity is important in patients with chronic obstructive pulmonary disease (COPD). In this patient population, decreased physical activity has been associated with acute exacerbations [1], hospitalizations, and greater mortality [2-3]. Moderate to high levels of regular physical activity have been shown to be associated with a reduction in smokingrelated lung function decline and COPD risk among smokers [4]. The ability to extend monitoring of ambulation and physical activity from the supervised clinic setting to the free-living home environment may promote novel applications that allow maintenance of exercise benefits following a supervised pulmonary rehabilitation program, early detection of COPD exacerbations, and

\footnotetext{
Abbreviations: $\mathrm{COPD}=$ chronic obstructive pulmonary disease, $\mathrm{CV}=$ coefficient of variation, $\mathrm{FEV}_{1}=$ force expiratory volume in 1 second, VA = Department of Veterans Affairs.

* Address all correspondence to Marilyn L. Moy, MD, MSc; VA Boston Healthcare System, Pulmonary and Critical Care Section, 1400 VFW Parkway, 111PI, West Roxbury, MA 02132; 857-203-6622; fax: 857-203-5670.

Email: marilyn.mov@va.gov

DOI: 10.1682/JRRD.2007.09.0147
} 
assessment of response to therapeutic interventions in COPD clinical trials [5-7].

The use of body-worn sensors to measure physical activity, such as walking, in free-living individuals in nondisabled and disease states has gained popularity. Wearable sensors have been developed, tested, and used in the nondisabled population. However, little is known about their accuracy in patients with chronic disease. Pedometers, or step counters, are typically worn on the belt or waistband and detect vertical acceleration of the hip during gait cycles. Although simple to use and inexpensive, pedometers are limited by their nonspecificity and inability to store long-term data, are affected by the amount of soft tissue at the waist, and require subjects to remember to put them on each time they are active [8-9]. Multiaxial accelerometers have been used to measure physical activity in addition to step counts. However, their output is highly variable and difficult to put into clinical context. Interpretation depends on calibration equations and cutoff points for defining light, moderate, vigorous, and total activity [10-15]. To date, these cutoff points have been defined for nondisabled, young adults in the supervised setting with correlations to maximum oxygen consumption on cardiopulmonary exercise tests, not during free-living conditions in the population being studied.

The ActiHealth uniaxial accelerometer (FitSense Technology, Inc; Southborough, Massachusetts) (Figure 1) overcomes many of the existing limitations of pedometers and accelerometers. The ActiHealth accelerometer is a lightweight and unobtrusive device that attaches to the shoe and continuously records step counts when a person walks. A sensor is used to capture the physiological waveforms associated with a foot stride [16]. Up to 30 days of step count data from the device can be wirelessly and securely transferred via the Internet to a database for storage and retrieval. The single coin-cell battery lasts for 1 to 2 years depending on use. The device remains secured to the shoe so subjects do not have to attach the device each time they walk. Subjects do not have to push buttons, recharge batteries, or record numbers.

In this study, we determined the intra- and interdevice coefficients of variation (CVs) of the ActiHealth accelerometer. We determined the accuracy of the accelerometer in nondisabled subjects and in subjects with COPD and identified the clinical variables that predict device performance.
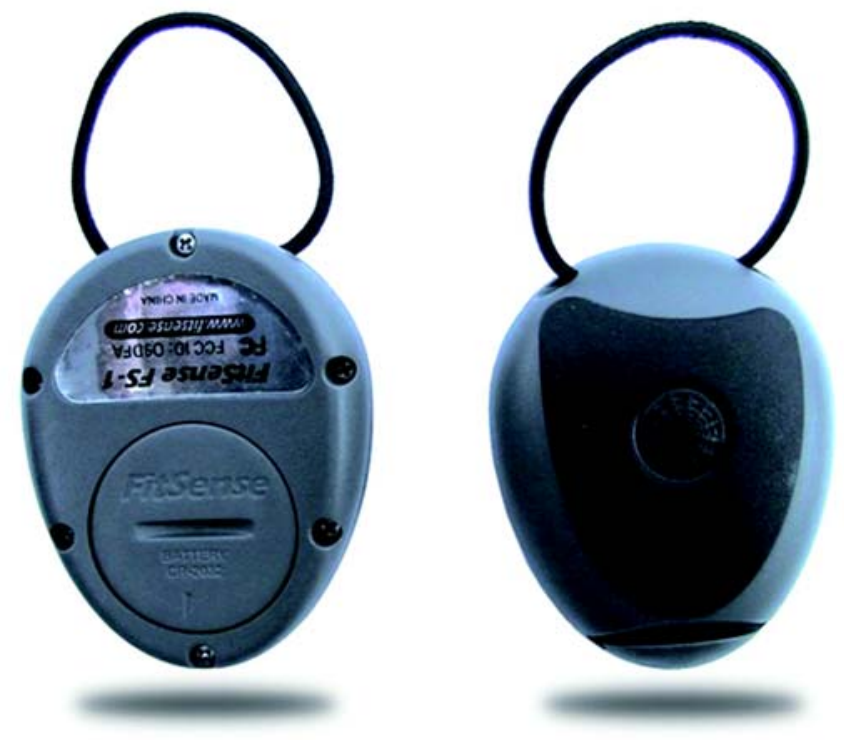

Figure 1.

ActiHealth accelerometer (FitSense Technology, Inc; Southborough, Massachusetts).

\section{METHODS}

\section{Nondisabled Subjects}

To determine the intra- and interdevice CVs of the ActiHealth accelerometer, two of the investigators (MLM and KRM) both completed 5 walking studies (see “Accelerometer and Walking Studies" section, p. 613 for description) with each of nine ActiHealth accelerometers (total of 90 trials) over 2 days. Fifteen nondisabled males who had no known pulmonary disease performed a single walking study wearing an accelerometer on each foot to determine the accuracy of the device.

\section{Subjects with COPD}

Forty-six men with COPD were enrolled from a general pulmonary clinic, and each performed a single walking study wearing an accelerometer on each foot. COPD was defined as having a force expiratory volume in $1 \mathrm{sec}-$ ond $\left(\mathrm{FEV}_{1}\right) /$ forced vital capacity $<0.70$ and a smoking history of $>10$ pack-years or computed tomography evidence of emphysema. Subjects who wore slide-on shoes, could not walk, or required assistance for ambulation (cane, walker, or wheelchair) were excluded. Medical records were reviewed for diagnoses that could affect the lower limbs and ambulation. Diagnoses of osteoarthritis or degenerative joint disease, hip or knee replacements, rheumatoid arthritis, chronic low back pain, lumbar spine 
disease, peripheral vascular disease, or peripheral neuropathy were noted. The medical record was also reviewed for the most recent spirometry performed. Evidence of a COPD exacerbation, defined as subjects using antibiotics or oral corticosteroid therapy, at the time of the study was obtained by medical record review.

The protocol was approved by the Department of Veterans Affairs (VA) Boston Healthcare System Committee on Human Research, and informed consent was obtained from each subject.

\section{Accelerometer and Walking Studies}

During each walking study, participants walked a predetermined level course of 800 feet and were instructed to walk at their usual speed. Two accelerometers were chosen from a set of nine, and each subject wore one on the right and left foot. The accelerometer was mounted on the top of the shoe and secured with the laces or Velcro ${ }^{\circledR}$ straps. Every step taken by the right foot was manually counted by one of the investigators (MLM or KRM) and multiplied by 2 for the total manual step count. The time to walk the course was used to calculate usual walking speed. Supplemental oxygen, if prescribed for ambulation, and rests were permitted in subjects with COPD.

\section{Statistical Analysis}

Accuracy was defined as the percent step capture, (accelerometer step counts/manual step counts) $\times 100$. We calculated the intra- and interdevice CVs for the nine devices used in the 90 trials by MLM and KRM. For the 46 subjects with COPD, correlations between percent step capture and the continuous variables were assessed by Spearman correlation coefficients.

Linear regression methods (PROC MIXED, SAS, version 9.2, SAS Institute; Cary, North Carolina) identified the significant predictors of percent step capture [17]. Variables significant at the 0.10 level were assessed in multivariate models. The 92 trials (46 walking studies $\times$ 2 feet, each with a different accelerometer) in the 46 subjects with COPD were analyzed with SAS PROC MIXED, which adjusted for the correlated data from each subject wearing a different accelerometer on each foot during a single walking study.

\section{RESULTS}

In the 90 trials completed by MLM and KRM (9 devices $\times 5$ trials $\times 2$ investigators), the accuracy was
98 percent. The accelerometer had an intradevice CV that ranged from 0.008 to 0.025 and an interdevice $\mathrm{CV}$ of 0.64 . The average speeds for walking trials performed by MLM and KRM were $3.1 \pm 0.07 \mathrm{mph}$ and $3.2 \pm 0.09 \mathrm{mph}$, respectively (all data presented as mean \pm standard deviation unless otherwise noted). For the 15 nondisabled male subjects (mean age $56 \pm 12$ years), the average walking speed was $2.8 \pm 0.42 \mathrm{mph}$. The median percent step capture or accuracy was 96 percent (interquartile range 81\%-98\%).

The 46 men (mean age $71 \pm 9$ years) with predominantly moderate to severe COPD (Global Initiative for Chronic Obstructive Lung Disease stages II and III [18]) had a mean $\mathrm{FEV}_{1}$ of $1.73 \pm 0.57 \mathrm{~L}(53 \% \pm 18 \%$ of predicted values) (Table 1). The median percent step capture or accuracy was 86 percent (interquartile range $72 \%-$ $96 \%)$. Their average walking speed was $2.2 \pm 0.39 \mathrm{mph}$. Eighteen subjects (39\%) had a concurrent medical diagnosis of osteoarthritis or degenerative joint disease, hip or knee replacements, rheumatoid arthritis, chronic low back pain, lumbar spine disease, peripheral vascular disease, or peripheral neuropathy. Three subjects were experiencing a COPD exacerbation at the time of the walking study, six subjects used supplemental oxygen, and four subjects briefly stopped to rest. For all 92 trials in the COPD sub-

Table 1.

Characteristics of subjects with chronic obstructive pulmonary disease (COPD) $(N=46)$.

\begin{tabular}{lc}
\hline \multicolumn{1}{c}{ Characteristic } & Mean \pm SD or $\boldsymbol{n ~ ( \% ) ~}$ \\
\hline Age (yr) & $71 \pm 9$ \\
Speed (mph) & $2.2 \pm 0.39$ \\
$\mathrm{FEV}_{1}(\mathrm{~L})^{*}$ & $1.73 \pm 0.57$ \\
$\mathrm{FEV}_{1}$ (\% predicted) & $53 \pm 18$ \\
Manual Step Count & $411 \pm 78$ \\
Accelerometer Step Count & $310 \pm 100$ \\
GOLD Stage & \\
Mild & $2(5)$ \\
Moderate & $23(52)$ \\
Severe & $15(34)$ \\
$\quad$ Very Severe & $4(9)$ \\
COPD Exacerbation & $3(7)$ \\
Used Oxygen During Walk & $6(13)$ \\
Lower-Limb Problem & $18(39)$ \\
Stopped During Walk to Rest & $4(9)$ \\
Wore Shoes with Velcro Straps & $6(13)$ \\
\hline
\end{tabular}

${ }^{*}$ Two subjects did not have spirometry data.

$\mathrm{FEV}_{1}=$ force expiratory volume in 1 second, GOLD = Global Initiative for Chronic Obstructive Lung Disease, SD = standard deviation. 
jects, the accelerometer undercounted the steps (mean accelerometer step count of $310 \pm 100$ vs mean manual step count of $411 \pm 78$ ) (Table 1). We defined acceptable accuracy as percent step capture of $\geq 90$ percent. Plot of usual walking speed by percent step capture revealed that at speeds $\geq 2.2 \mathrm{mph}$, the average walking speed for the COPD group, subjects were more likely to have $\geq 90$ percent step capture (Figure 2). For speeds $<2.2 \mathrm{mph}, 8$ of the 42 trials (19\%) had $\geq 90$ percent step capture, and for speeds $\geq 2.2 \mathrm{mph}, 33$ of the 50 trials $(66 \%)$ had $\geq 90$ percent step capture.

In univariate linear regression models, speed and lower-limb problems were significant predictors of percent step capture (Table 2). Speed was poorly correlated with $\mathrm{FEV}_{1}$ percent predicted (Spearman $r=0.10$ ). Neither $\mathrm{FEV}_{1}$ percent predicted, COPD exacerbation, nor the person counting steps (MLM or KRM) was associated with percent step capture. In multivariate models, speed was the most significant determinant of percent step capture ( $p=0.004$, Table 3$)$. For each increase in miles per hour, the percent step capture increased 24 points (95\% confidence interval 8 to 40) (Table 3).

\section{DISCUSSION}

This study demonstrates that the ActiHealth accelerometer is accurate in a nondisabled cohort. However, its accuracy declines when it is used in subjects with COPD. Usual walking speed is the most important predictor of percent step capture and accuracy of the accelerometer. Before use of the ActiHealth accelerometer, walking speed and percent step capture should be verified in each subject.

Little is published in the literature about the accuracy of pedometers or accelerometers in the COPD population [19]. The present study is the first to assess the accuracy

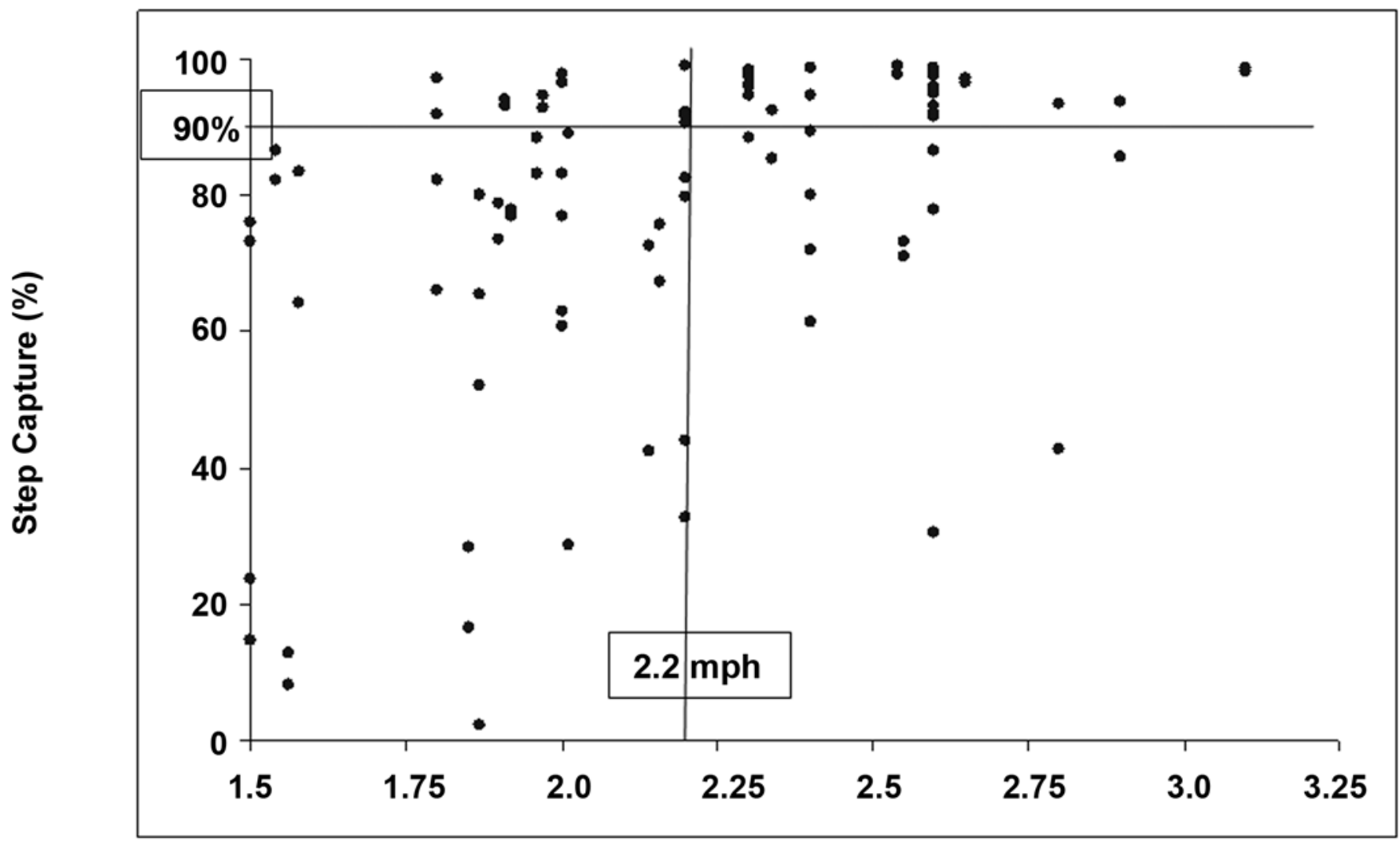

\section{Speed (mph)}

Figure 2.

Relationship between walking speed (mph) and percent step capture. We defined acceptable accuracy as percent step capture $\geq 90 \%$. Average speed was $2.2 \mathrm{mph}$. For speeds $<2.2 \mathrm{mph}, 8$ of 42 trials (19\%) had $\geq 90 \%$ step capture. For speeds $\geq 2.2 \mathrm{mph}, 33$ of 50 trials (66\%) had $\geq 90 \%$ step capture. 
Table 2.

Univariate linear regression models of predictors of percent step capture in chronic obstructive pulmonary disease (COPD) ( $N=92$ accelerometer trials).

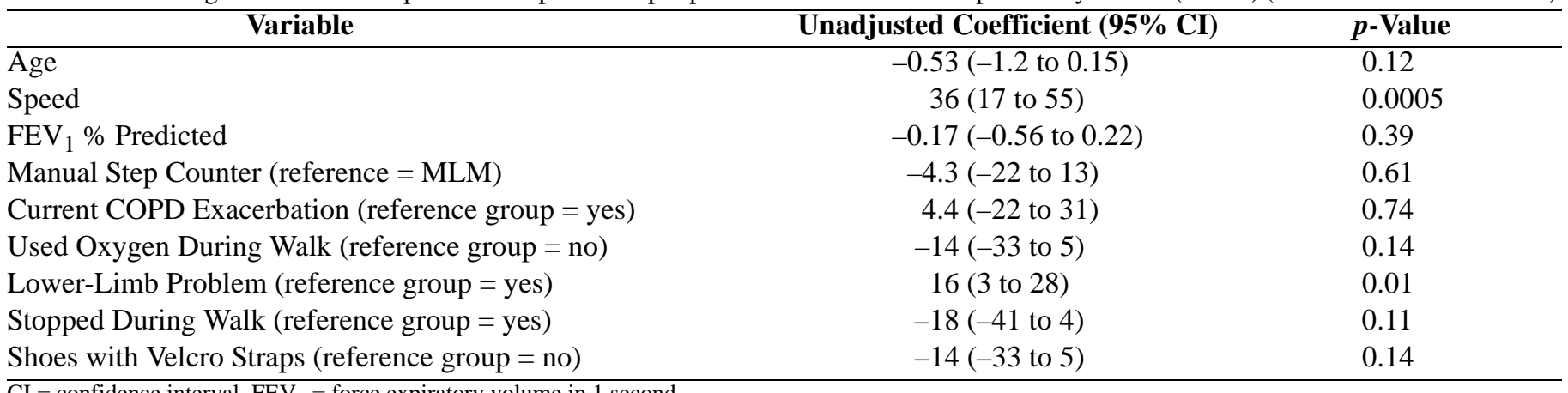

$\mathrm{CI}=$ confidence interval, $\mathrm{FEV}_{1}$ = force expiratory volume in 1 second.

Table 3.

Multivariate linear regression model of determinants of percent step capture in chronic obstructive pulmonary disease ( $N=92$ accelerometer trials).

\begin{tabular}{lcc}
\multicolumn{1}{c}{ Variable } & Adjusted Coefficient (95\% CI) & $\boldsymbol{p}$-Value \\
\hline Speed (mph) & 24 (8 to 40) & 0.004 \\
Lower-Limb Problem (reference group = yes) & 9.0 (-3.6 to 22) & 0.16 \\
\hline CI = confidence interval. & &
\end{tabular}

of an accelerometer device against the "gold standard" of manual step counts in the COPD population. Other devices used in the COPD population have been shown to have concurrent validity by correlations with lung function, exercise capacity, or dyspnea; however, the accuracy of these devices in the field is unknown. For example, a triaxial accelerometer, the RT3 activity monitor (Stayhealthy, Inc; Monrovia, California), has been used in subjects with COPD. Steele et al. showed moderate correlations between the vector magnitude units and existing measures of disease status, such as lung function, 6-minute walk distance, and dyspnea [20-22]. The DynaPort Activity Monitor, a triaxial accelerometer (375 g) (McRoberts; The Hague, the Netherlands), was shown to be accurate in assessing time spent walking, cycling, standing, sitting, and lying down compared with video recordings [23]. Time spent walking was shown to be moderately correlated with lung function, muscle function, and exercise capacity [24]. Similarly, the SenseWear ${ }^{\circledR}$ armband (Bodymedia, Inc; Pittsburgh, Pennsylvania), a biaxial accelerometer ( $80 \mathrm{~g}$ ) worn on the arm, measures steps per day, which has been shown to correlate with $\mathrm{FEV}_{1}$ and 6-minute walk distance [25]. Our results indicate that assessing the accuracy of wearable sensors in persons with COPD is important. Subject characteristics, such as walking speed, may influence whether each step or physical activity is accurately detected. Our results suggest that sensors may have very different performance properties in subjects with COPD compared with nondisabled subjects.

In this cohort of subjects with predominantly moderate to severe COPD, walking speed was poorly correlated with $\mathrm{FEV}_{1}$ percent predicted. This finding suggests that excluding subjects with COPD who walk at slow speeds (in whom the accelerometer would be inaccurate) in future studies would not differentially exclude those with low $\mathrm{FEV}_{1}$ percent predicted. Conversely, $\mathrm{FEV}_{1}$ percent predicted cannot be used to predict walking speed or likelihood of accurate step capture by the ActiHealth accelerometer.

In this report, we have established the intra- and interdevice CVs of the ActiHealth accelerometer and have also assessed its accuracy in nondisabled subjects and in subjects with COPD. In the subset of patients with COPD who have acceptable accuracy ( $\geq 90 \%$ step capture), we plan to perform additional studies using the ActiHealth accelerometer to assess the day-to-day variability of step counts, its responsiveness to change in clinical status, the relationship between step counts and distance walked, and the relationship between step counts and clinical measures of COPD severity. Understanding these relationships will guide future clinical and research uses of the ActiHealth accelerometer in the COPD population. Furthermore, technical changes in the ActiHealth accelerometer need to 
be developed to improve its sensitivity and accuracy in the elderly population with chronic disease.

\section{CONCLUSIONS}

The ActiHealth accelerometer is accurate in nondisabled subjects and in a subset of patients with COPD. Walking speed is the most significant predictor of accelerometer accuracy. Before use of the ActiHealth accelerometer, researchers and clinicians should verify walking speed and percent step capture in each subject. In general, the accuracy of wearable sensors should be assessed in the population that is being studied, since they may have different performance properties compared with nondisabled subjects.

\section{ACKNOWLEDGMENTS}

We thank Kelly Stolzmann for her assistance.

This material was based on work supported by the VA, Veterans Health Administration, Rehabilitation Research and Development Service, at the VA Boston Healthcare System, Boston, Massachusetts, through a VA Career Development Award to Dr. Moy and by the National Institutes of Health, National Institute of Child Health and Human Development, grant RO1 HD42141 to Dr. Garshick.

This study was initiated by the investigators, who do not receive any financial support from FitSense, Inc, and the results of the present study do not constitute endorsement of the product by the authors. FitSense, Inc, did not have any involvement in the study design; data collection, analysis, or interpretation; and writing or submission of this article.

The authors have declared that no competing interests exist.

\section{REFERENCES}

1. Donaldson GC, Wilkinson TM, Hurst JR, Perera WR, Wedzicha JA. Exacerbations and time spent outdoors in chronic obstructive pulmonary disease. Am J Respir Crit Care Med. 2005;171(5):446-52. [PMID: 15579723]

2. Garcia-Aymerich J, Lange P, Benet M, Schnohr P, Antó JM. Regular physical activity reduces hospital admission and mortality in chronic obstructive pulmonary disease: A population based cohort study. Thorax. 2006;61(9):772-78. [PMID: 16738033]

3. Martinez FJ, Foster G, Curtis JL, Criner G, Weinmann G, Fishman A, DeCamp MM, Benditt J, Sciurba F, Make B, Mohsenifar Z, Diaz P, Hoffman E, Wise R; NETT Research Group. Predictors of mortality in patients with emphysema and severe airflow obstruction. Am J Respir Crit Care Med. 2006;173(12):1326-34. [PMID: 16543549]

4. Garcia-Aymerich J, Lange P, Benet M, Schnohr P, Antó JM. Regular physical activity modifies smoking-related lung function decline and reduces risk of chronic obstructive pulmonary disease: A population-based cohort study. Am J Respir Crit Care Med. 2007;175(5):458-63. [PMID: 17158282]

5. Moy ML, Mentzer SJ, Reilly JJ. Potential clinical applications of measuring cumulative free-living activity in chronic obstructive pulmonary disease. IEEE Eng Med Biol. 2003;22:89-95.

6. Sewell L, Singh SJ, Williams JE, Collier R, Morgan MD. Can individualized rehabilitation improve functional independence in elderly patients with COPD? Chest. 2005; 128(3):1194-1200. [PMID: 16162706]

7. Coronado M, Janssens JP, De Muralt B, Terrier P, Schutz Y, Fitting JW. Walking activity measured by accelerometry during respiratory rehabilitation. J Cardiopulm Rehabil. 2003;23(5):357-64. [PMID: 14512781]

8. Schneider PL, Crouter SE, Bassett DR. Pedometer measures of free-living physical activity: Comparison of 13 models. Med Sci Sports Exerc. 2004;36(2):331-35. [PMID: 14767259]

9. Tudor-Locke C, Williams JE, Reis JP, Pluto D. Utility of pedometers for assessing physical activity: Construct validity. Sports Med. 2004;34(5):281-91. [PMID: 15107007]

10. Welk GJ, McClain JJ, Eisenmann JC, Wickel EE. Field validation of the MTI Actigraph and BodyMedia armband monitor using the IDEEA monitor. Obesity (Silver Spring). 2007;15(4):918-28. [PMID: 17426327]

11. Jacobi D, Perrin AE, Grosman N, Doré MF, Normand S, Oppert JM, Simon C. Physical activity-related energy expenditure with the RT3 and TriTrac accelerometers in overweight adults. Obesity (Silver Spring). 2007;15(4): 950-56. [PMID: 17426330]

12. Powell SM, Rowlands AV. Intermonitor variability of the RT3 accelerometer during typical physical activities. Med Sci Sports Exerc. 2004;36(2):324-30. [PMID: 14767258]

13. Nichols JF, Morgan CG, Sarkin JA, Sallis JF, Calfas KJ. Validity, reliability, and calibration of the Tritrac accelerometer as a measure of physical activity. Med Sci Sports Exerc. 1999;31(6):908-12. [PMID: 10378921]

14. Esliger DW, Tremblay MS. Technical reliability assessment of three accelerometer models in a mechanical setup. Med Sci Sports Exerc. 2006;38(12):2173-81. [PMID: 17146326] 
15. Ham SA, Reis JP, Strath SJ, Dubose KD, Ainsworth BE. Discrepancies between methods of identifying objectively determined physical activity. Med Sci Sports Exerc. 2007;39(1):52-58. [PMID: 17218884]

16. Weyand PG, Kelly M, Blackadar T, Darley JC, Oliver SR, Ohlenbusch NE, Joffe SW, Hoyt RW. Ambulatory estimates of maximal aerobic power from foot-ground contact times and heart rates in running humans. J Appl Physiol. 2001;91(1):451-58. [PMID: 11408463]

17. Kleinbaum DJ, Kupper LL, Muller KE, Nizam A. Applied regression analysis and other multivariable methods. 3rd ed. Boston (MA): Duxbury Press; 1998.

18. Rabe KF, Hurd S, Anzueto A, Barnes PJ, Buist SA, Calverley P, Fukuchi Y, Jenkins C, Rodriguez-Roisin R, Van Weel C, Zielinksi J; Global Initiative for Chronic Obstructive Lung Disease. Global strategy for the diagnosis, management, and prevention of chronic obstructive pulmonary disease: GOLD executive summary. Am J Respir Crit Care Med. 2007;176(6):532-55. [PMID: 17507545]

19. Pitta F, Troosters T, Probst VS, Spruit MA, Decramer M, Gosselink R. Quantifying physical activity in daily life with questionnaires and motion sensors in COPD. Eur Respir J. 2006;27(5):1040-55. [PMID: 16707399]

20. Steele BG, Belza B, Cain K, Warms C, Coppersmith J, Howard J. Bodies in motion: Monitoring daily activity and exercise with motion sensors in people with chronic pulmonary disease. J Rehabil Res Dev. 2003;40(5 Suppl 2):45-58. [PMID: 15074453]
21. Steele BG, Holt L, Belza B, Ferris S, Lakshminaryan S, Buchner DM. Quantitating physical activity in COPD using a triaxial accelerometer. Chest. 2000;117(5):1359-67.

[PMID: 10807823]

22. Steele BG, Belza B, Hunziker J, Holt L, Legro M, Coppersmith J, Buchner D, Lakshminaryan S. Monitoring daily activity during pulmonary rehabilitation using a triaxial accelerometer. J Cardiopulm Rehabil. 2003;23(2):139-42. [PMID: 12668936]

23. Pitta F, Troosters T, Spruit MA, Decramer M, Gosselink R. Activity monitoring for assessment of physical activities in daily life in patients with chronic obstructive pulmonary disease. Arch Phys Med Rehabil. 2005;86(10):1979-85.

[PMID: 16213242]

24. Pitta F, Troosters T, Spruit MA, Probst VS, Decramer M, Gosselink R. Characteristics of physical activities in daily life in chronic obstructive pulmonary disease. Am J Respir Crit Care Med. 2005;171(9):972-77. [PMID: 15665324]

25. Watz H, Waschki B, Meyer T, Kanniess F, Magnussen H. Quantification of physical activity in daily life of patients with COPD: Comparison of two devices and two parameters of activity measurement [abstract]. Am J Respir Crit Care Med. 2007;175:A369.

Submitted for publication September 18, 2007. Accepted in revised form December 17, 2007. 